\title{
Fertility Projections in a European Context: A Survey of Current Practices among Statistical Agencies
}

\author{
Rebecca Folkman Gleditsch ${ }^{1}$, Astri Syse ${ }^{1}$, and Michael J. Thomas ${ }^{1}$
}

\begin{abstract}
Projection studies have often focused on mortality and, more recently, migration. Fertility is less studied, although even small changes can have significant repercussions for the size and age structure of future populations. Across Europe, there is no consensus on how fertility is best projected. In this article, we identify different approaches used to project fertility among statistical agencies in Europe and provide an assessment of the different approaches according to the producers themselves.

Data were collected using a mixed-method approach. First, European statistical agencies answered a questionnaire regarding fertility projection practices. Second, an in-depth review of select countries was performed.

Most agencies combine formal models with expert opinion. While many attempt to maximise the use of relevant inputs, there is more variation in the detail of outputs, with some agencies unable to account for changing age patterns. In a context of limited resources, most are satisfied with their approaches, though some are assessing alternative methodologies to improve accuracy and increase transparency.

This study highlights the diversity of approaches used in fertility projections across Europe. Such knowledge may be useful to statistical agencies as they consider, test and implement different approaches, perhaps in collaboration with other agencies and the wider scientific community.
\end{abstract}

Key words: Europe; fertility; forecasts; methods; population projections.

\section{Introduction}

Population projections are widely used by governments, policy makers, planners, and organizations across the world. National population projections are typically produced by national statistical agencies, but international agencies such as Eurostat and the United Nations (UN) also publish projections at both national and continental levels. Assumptions about future developments in fertility, mortality and international migration constitute the basis for national population projections, and the term projection is used for any estimate of the future population, including less likely ones.

Historically, studies of projection methodology have focused almost exclusively on mortality (cf. e.g., Lee and Carter 1992; Li and Lee 2005; Hyndman et al. 2013), although recent attention has also been paid to methodological advances in the projection of international migration (e.g., Bijak 2011; Cappelen et al. 2015; Disney et al. 2015; Raymer and Wiśniowski 2018). Studies evaluating the methodological approaches used in fertility projections have been far rarer, although notable exceptions exist (cf. for instance

\footnotetext{
${ }^{1}$ Statistics Norway, Department of Research, PO Box 2633 St. Hanshaugen, N-0131 Oslo, Norway. Emails: rebeccafg@gmail.com, astri.syse@ssb.no, and michael.thomas@ssb.no
} 
Hyndman and Ullah 2007; Bohk-Ewald et al. 2018). The limited body of research into the different methodologies employed in fertility projections is unfortunate because even a small change in fertility can have a substantial cumulative effect on the population size and age structure (UN DESA 2013). Moreover, given recent trends, fertility has risen to prominence as a key topic of political and public interest, especially in more developed countries that are experiencing low and downward trends in birth rates (UN DESA 2019a).

The overall aim of this study is to explore the different approaches used in the development of assumptions about future fertility in Europe, and to assess the relative strengths and weaknesses of these approaches based on self-reported evaluations derived from the relevant statistical agencies. To achieve this goal, a mixed-method study was undertaken. First, with the aim of providing a representation of the diversity of inputs, outputs and approaches used across Europe, we present a summary of an in-depth document review of fertility projections for selected European countries. Following this, a comprehensive survey of 32 statistical agencies involved in national population projections in Europe is used to reveal the self-reported evaluations of the approaches used, as well as suggestions for how fertility might be projected in the absence of limited resources.

In providing this unique overview of fertility projections in Europe, we hope that readers will be better placed to evaluate the relative sophistication and usefulness of populations projections when they encounter them. Furthermore, the scientific community might be better able to acknowledge the unique needs of the statistical agencies, whereas projection producers may be given insights into the extent to which their current methods are adequate or contemplate whether alternative approaches might be worth considering, perhaps in collaboration with other producers and/or experts in the wider scientific community.

\section{Background}

\subsection{Recent Developments in Fertility}

In recent decades, many countries across Europe have witnessed substantial changes in the total fertility rate (TFR) - a summary measure of the number of children who would be born to a woman if she were to pass through the reproductive ages bearing children according to a current schedule of age-specific fertility rates (ASFRs). Indeed, according to Eurostat (2021), the TFR for the entire EU increased from 1.43 in 2001 to 1.57 in 2010. It decreased slightly to 1.51 in 2013 and has since stabilised at a level just above 1.5 (in 2019 it was 1.53). Beyond the variations observed over time at the EU level, considerable differences between the constituent nations of the EU also exist. According to Eurostat (2021) figures for 2019, France reported the highest TFR (1.86), followed by Romania (1.77) and Ireland, Sweden and the Czech Republic (all 1.71). The lowest TFR was recorded in Malta (1.14), followed by Spain (1.23), Italy (1.27), Cyprus (1.33), Greece and Luxembourg (both 1.34). In most countries, the TFR declined considerably between 1980 and the early 2000s. By 2000, values had fallen below 1.30 in Bulgaria, the Czech Republic, Greece, Spain, Italy, Latvia, Slovenia and Slovakia. Thereafter, the TFR has increased in many places, and by 2019 , the majority of countries reported TFRs above 1.30. As such, there has been a trend towards convergence in TFRs across Europe. In 1970, the disparity between the highest (Ireland) and the lowest (Finland) TFR was around 2.0. 
By 1990, this difference had decreased to 1.1 , by 2010 to 0.8 and by 2019 to 0.7 , with different countries displaying the highest and lowest fertility across years (Eurostat 2021).

Variations in fertility both over time and across countries can pose problems for agencies responsible for projecting fertility (Sobotka 2017). For instance, producers struggled to anticipate the persistence of the downward trend in fertility observed over the last decade, with many projecting fertility at similar levels to those observed in the years running up to the production of the projection - a situation known as 'assumption drag' (Ascher 1979). The failure to predict the continuation of the current downward trend in many countries has resulted in a persistent overestimation of fertility in countries including Belgium, Finland, Italy, Ireland, the Netherlands, Norway, Sweden and Denmark.

As period fertility is utilized in most national projections, this study primarily focuses on methods used to project TFRs. The TFR remains the most widely used period fertility measure for two main reasons:

1. It is unaffected by differences or changes in age-sex composition (in contrast to the number of births) and is thus comparable over time and across countries; and

2. It provides an easily understandable measure of hypothetical completed fertility. The terms fertility, total fertility and TFR are therefore used interchangeably in a period perspective, unless otherwise stated.

The TFR is, however, highly sensitive to changes in the timing of births to women of reproductive age. Thus, many projection agencies also examine changes in cohort fertility, which reflects the average number of births by all women born in the same calendar year. A drawback to this measure is that it can only be calculated when women have completed their childbearing years, usually assumed to be around age 45 - although cohort fertility for cohorts still of reproductive age can be useful in providing some idea of the degree to which women are choosing to delay or forego fertility (Zeman et al. 2018). Completed cohort fertility may be considerably different from that implied by current TFRs because postponed births can be recovered (Bongaarts and Feeney 1998). Consequently, cohort fertility typically varies less over time than period fertility.

Producers of projections can also consider the age schedules of fertility, that is, the distribution of births across age groups, as a means of identifying dynamics such as postponement. The age schedule might slide toward higher or lower ages, reflecting postponement or advancement of births, with consequences for the mean age of childbirth (MAC). Indeed, while the TFR has been declining over the last decade, the MAC for the EU rose from an average of 29.0 years in 2001 to 30.9 years in 2009 (Eurostat 2021). In addition, the ASFRs reflect a trend towards greater postponement: While the ASFRs were highest among women aged 25-29 years in 2001, they are now highest among women aged 30-34 years. Fertility above age 35 is also rising, a trend that is fairly consistent across the EU (Eurostat 2021).

\subsection{Approaches to Fertility Projections}

A fertility projection may refer both to the fertility assumptions made (usually future TFR levels) and to the results from such assumptions, for instance when assumed probabilities or rates for future fertility (usually in the form of ASFRs) are used to estimate the future 
number of births in a population. Since different assumptions regarding future TFRs may be made, it is common for producers to provide several future fertility levels/scenarios.

The various approaches that national statistical agencies take when producing official fertility projections often differ from the published methods employed within the wider scientific community. According to Bohk-Ewald et al. (2018), more than 20 methods exist to forecast cohort fertility, with more than 160 projection variants produced. These approaches range from naïve freezing of current ASFRs, to methods that use sophisticated statistical techniques or have a dominant grounding in demographic theory (ibid). Somewhat surprisingly, only four of the methods identified were found to consistently outperform the naïve freeze rate method in terms of accuracy. Only two methods produced reasonable uncertainty estimates. Defining 'state-of-the-art' in fertility forecasting is, therefore, not a simple task. Of the four best performing approaches identified by Bohk-Ewald et al. (2018), two were Bayesian approaches, which have relatively large demands in terms of input data, computational power and statistical knowhow. The other two methods were simple extrapolation methods, which are generally considered to be less demanding. For practical projection work, it is important to keep in mind that although the fertility forecasting methods proposed in scientific papers tend to be more complex, they do not necessarily perform better than the simpler approaches currently in use (Bohk-Ewald et al. 2018). Similar conclusions have been drawn elsewhere, with the 'freeze rates approach' shown to perform better than other, more complex, methods (Myrskylä 2021).

If we group fertility forecasting methodologies into four broad categories - (1) Extrapolative methods (e.g., De Beer 1990); (2) Parametric curve fitting models (e.g., Hadwiger 1940); (3) Demographic methods (e.g., Sobotka et al. 2011); and (4) Combinations of the above (e.g., Schmertmann et al. 2014) - it is difficult to find consensus in terms of which approach provides the most optimal results in the short- or longer-term. This is primarily because relatively few formal evaluations have been undertaken to determine how accurately the models project fertility across countries and time periods. What is more certain is that forecasting by fertility determinants like education or immigrant background does not beat aggregate forecasts, and that neither the short-term accuracy nor the uncertainty estimates are improved by forecasts of fertility determinants rather than observed trends (Bohk-Ewald et al. 2018; Myrskylä 2021).

\section{Data and Method}

This study comprises all Eurostat associated member countries, as well as Eurostat itself and the UN, and employs a simple mixed-method approach, utilizing both qualitative and quantitative data and analytic techniques. Data were collected in two steps: First, Eurostat, the UN and the national statistical agencies of Eurostat associated member countries were asked to respond to a questionnaire regarding current practice vis-à-vis the production of their fertility projections. The resulting findings comprise the main part of this article. Second, representative statistical agencies were selected for a more in-depth review, where survey responses were compared and complemented with an examination of readily available online information and documentation, as well as published reports and journal articles. A summary of this information is presented in the main text of this article, but a more extensive description of the individual countries is provided in online Supplemental Data 1. 
A pilot survey was distributed to the Nordic agencies (Denmark, Faroe Islands, Finland, Greenland, Iceland, and Sweden), prior to a joint Nordic population projection meeting in 2019. Based on the responses and feedback, an adjusted questionnaire was distributed to all Eurostat associated member countries during autumn 2019. Consequently, all results presented here are based on practices prior to that date. The survey letter and the survey itself is documented in Gleditsch and Syse (2020).

The survey was set up as an online questionnaire, distributed via a link in an email, with additional information in a survey letter. The survey was distributed to a total of 42 European national statistical agencies, Eurostat and the UN $(\mathrm{N}=44)$. After a maximum of three reminders, and subsequent to a presentation of preliminary results at a EurostatUNECE workshop in November 2019, all agencies responded. A total of 32 agencies produce fertility projections and are included in the analysis. The remaining 12 agencies do not produce fertility projections, and thus did not respond to the survey. Online Supplemental Data 2 contains an overview of the relevant agencies, along with an overview of the main projection websites.

The survey asked about the methods used for projecting fertility in the most recent population projection, as well as discrepancies between projected and observed fertility. Examples of the questions asked include: "Do you currently use a formal statistical model to project fertility?"; "In the data you use, what type of information is available?"; and; "If you could choose freely, do you have any suggestions of changes to the way your country projects fertility?".

In Section 5, we present survey results regarding each agency's current practices, the perceived benefits and drawbacks of the chosen approach, as well as suggestions for any proposed changes to the approach if there were fewer resource constraints. The results are summarized qualitatively and quantitatively. The different methods used by the participating countries are categorized into four broad groups: (1) Model-based deterministic projections; (2) Model-based probabilistic projections (frequentist and/or Bayesian); (3) Expert-opinion elicited projections; and (4) Historical developments/other methods. Historical developments encompass methods that use information obtained by examining changes in fertility trends over time, such as the development in the TFR, cohort fertility, MAC or other factors that correlate with fertility behaviour (e.g., changing educational, employment or partnership patterns). Less complex models may be used for some procedures, but discretionary choices are typically made to guide such use, at least for parts of the process.

A descriptive analysis of similarities and differences is performed to assess: (1) Which methods were most common; (2) the degree of satisfaction with the approach taken; (3) the public availability of documentation on the approach; and (4) the extent to which the accuracy of the projections is assessed in the short- and long-term. All countries were given an opportunity to assess and amend the summarized information, which helped to assure the quality of the analysis. Altogether 27 of the 32 agencies (84\%) took advantage of this opportunity.

Based on the survey responses, nine countries (Belgium, Denmark, Finland, France Germany, Italy, Norway, Poland and Sweden) together with the UN and Eurostat were selected for a more in-depth review, where survey responses were compared and complemented with an examination of readily available online information and 
documentation, as well as published reports and journal articles. The agencies were selected to illustrate the variation in the methods used to project fertility, and to provide an overview of the range of options available and utilized across Europe. Since the in-depth review provides the basis for insights into the differences among the various methods and approaches used, a summary of this review is presented first.

\section{Summary of In-Depth Review}

In this review, we summarize information gathered from available online documentation and published articles and/or reports from 11 agencies, that is, nine national statistical agencies, the UN and Eurostat, complemented by information gathered through the survey. Separate results for the individual agencies are provided in online Supplemental Data 1.

In summary, many different approaches are used to project fertility across Europe, with some agencies employing hybrids of various methods and/or approaches. Consequently, not all agencies are easily classified into the rigid framework we developed prior to undertaking this survey. As an example, France, which states in its documentation that it does not rely on models (cf. online Supplemental Data 1 and INSEE 2020), opted to place itself in the model-based deterministic category (cf. Table 1) when asked to quality assure the survey information.

Apart from Statistics Denmark (2019), all selected agencies use experts, either incorporating their opinions in their models or as an additional element in the fertility projections. For instance, experts had been used to discuss where to set long-term TFR levels or future age schedules, facilitate discussions of outer bounds for high or low alternatives, and/or contribute with input for the documentation to accompany the projected fertility figures. Norway and Sweden rely solely on research of historical developments and/or trend extrapolations and expert opinions. Eurostat, Belgium, Denmark, Finland, France, Germany and Poland use model-based deterministic methods, whereas the UN and Italy use a model-based probabilistic method.

Except for Denmark, all agencies provide more than one alternative for future fertility, to account for changing demographic trends and/or general uncertainty. While the UN has a full two-track system and produces both deterministic and probabilistic population projections, other countries provide some mixture of variations based on scenario-thinking or formalized uncertainty. This applies for instance to Sweden (cf. online Supplemental Data 1).

Of the agencies selected for the in-depth review, only Finland, Norway and Sweden do not account for changing age patterns in fertility (Statistics Finland 2019, 2020; Statistics Sweden 2019; Syse et al. 2020). Consequently, the current age schedule is assumed to remain constant in the future. Other agencies attempt to account for changing age schedules, most commonly by utilizing the model of Schmertmann (2003). In this model system, constrained quadratic splines are applied to three index ages, that is, ages where fertility (1) >0; (2) peaks; and (3) falls to half the peak, to determine the shape of the ASFR schedule. Some agencies also attempt to account for changing cohort fertility, parity and childlessness (cf. online Supplemental Data 1).

Most agencies account for differences in fertility in the short- and the long-term, either formally or informally. Most commonly, short-term fertility is determined via current 
fertility trends, while long-term fertility is assumed to converge towards a long-term level, wherein there appears to be fairly different opinions as to how this is best set. In Denmark, for instance, the long-term level is determined by examining the historic development of cohort fertility, assuming that this pattern is stable over time (Frank Hansen and Stephensen 2013, 11). In Belgium, economic determinants are weighed heavily in the short-term while structural trends (e.g., those pertaining to education, labour market participation, etc.) matter more in the longer-term (Vandresse 2020). Poland, on the other hand, assumes that fertility in the long-term will converge towards neighbouring countries with higher fertility (Statistics Poland 2014). In contrast, Italy uses the same method regardless of time horizon.

In terms of international comparisons, the UN, Eurostat and Poland all assume some convergence in future fertility levels between (neighbouring) countries (Eurostat 2019a, 2019b; Statistics Poland 2014; UN DESA 2019b, 2019c). Meanwhile, Finland, Norway and Sweden compare fertility trends in a Nordic setting, as part of their review of historical developments in trends. However, the findings are only used to inform future fertility assumptions in an informal manner.

All agencies included in the in-depth review state that they are currently working to improve their methodology. For instance, Norway reports that a model-based approach will be tested, allowing for changing age schedules in the future (Gleditsch et al. 2020), whereas France has conducted an experiment comparing results from their latest projection with those obtained using probabilistic methods (cf. Costemalle 2020). Belgium revised its fertility projection model in 2020 to account more adequately for the evolution of the fertility schedule over time and thus get a better handle on postponement (Vandresse 2020). Indeed, postponement was a recurrent concern among those agencies who had not yet attempted to account for changing age schedules.

\section{Survey Results}

In a European context, Eurostat, the UN and 30 national statistical agencies (71\%) produce fertility projections regularly (cf. online Supplemental Data 2). The type of methods utilized and the available resources to project fertility vary markedly and relate in part to how populous the countries are. Notably, the population ranges from 49,000 in the Faroe Islands (2017) to more than 80 million in both Germany (2019) and Turkey (2019).

\subsection{Resources Available to Produce Fertility Projections}

The survey asked about the number of persons involved in fertility projections, their field and highest level of education, the time allocated to projection work, and the frequency of publication of projections. It also enquired about the level of detail in available input data. In summary, the average number of people involved in the fertility projections was three (ranging from one to more than five), and the majority had a master's or doctoral degree. The most common backgrounds included statistics, demography, and economics, but backgrounds in health and social sciences were also mentioned. Most countries reported spending an average of two months per year (ranging from one to more than four) on fertility projections and most agencies make updates on an annual $(\mathrm{N}=6)$, biennial $(\mathrm{N}=6)$ or triennial $(\mathrm{N}=6)$ basis. Nine agencies make updates every fifth year, while two update 
every tenth year. A further two have been unable to update according to plan, publishing their last projections in 2014. At the other extreme, one agency reported that they make updates monthly.

Figure 1 presents the use of certain input data in fertility projections. All 32 agencies use maternal age, most commonly in single years $(90 \%)$. The remaining use five-year age groups. Whereas the vast majority use yearly information on births (94\%), some use (additional) information from multiple years. Country of origin was used by approximately one-third of the agencies, while only a few countries drew on data related to household type (3\%), ethnicity (3\%), mother's education (6\%), and marital status $(6 \%)$. Sub-national geography was used by approximately one-third of the agencies (38\%). Just two agencies reported that the quality of their input data was poor.

\subsection{Statistical Methods and the Use of Experts}

Respondents were asked whether they use a formal statistical model to project fertility and whether they use different methods for short-, medium-, and long-term projections. The survey also enquired about the published number of fertility scenarios and/or levels, and whether they involve any experts in their fertility projections. The results, summarized in Table 1 , show that $56 \%$ currently utilize a formal statistical model to project fertility. Such models are applied in countries with large as well as small populations.

Of the 16 agencies that report using a deterministic model-based approach, much variation exists in terms of what this approach actually constitutes. For instance, Switzerland does not use a formal model to project the TFR, but a model is used to produce the age structure. No formal model is used at the national level in Turkey either, as fertility assumptions are set in response to expert opinion. However, a mathematical convergence model is used to adjust the sub-regional-provincial fertility levels in Turkey to the national figures, both for the TFR and ASFRs. Other examples include first using one model to recover to the latest observed cohort fertility, then using a different model to tempo adjust the fertility, before the Hadwiger function (1940) is employed to estimate ASFRs (e.g.,

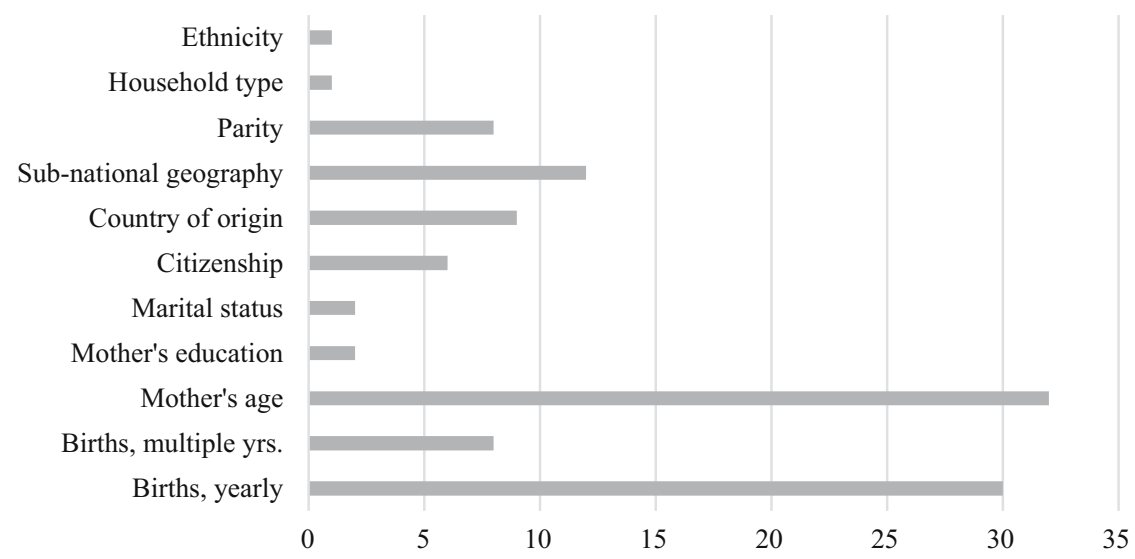

Fig. 1. The number of agencies using specific inputs to project fertility.

Note: The total number of agencies is 32 . Contact information for agencies that rely on specific inputs may be obtained from the authors. 
Table 1. Categorization of fertility projection methods.

\begin{tabular}{|c|c|}
\hline Type of fertility projection & Classification of countries and organizations \\
\hline 1. Model-based, deterministic & $\begin{array}{l}\text { Austria, The Czech Republic, Belgium, Denmark, } \\
\text { Eurostat, Finland, France, Germany, Greenland, } \\
\text { Poland, Portugal, Romania, Spain, Ukraine, UK, UN. }\end{array}$ \\
\hline 2. Model-based, probabilistic ${ }^{a}$ & Faroe Islands, Iceland, Italy, Netherlands, UN \\
\hline 3. Expert opinion ${ }^{b}$ & $\begin{array}{l}\text { Belgium, The Czech Republic, Estonia, Finland, } \\
\text { France, Germany, Hungary, Iceland, Ireland, Italy, } \\
\text { Luxembourg, Netherlands, Norway, Poland, Portugal, } \\
\text { Slovakia, Spain, Sweden, Switzerland, Turkey, UK, } \\
\text { Ukraine }\end{array}$ \\
\hline $\begin{array}{l}\text { 4. Historical developments/ } \\
\text { other methods }\end{array}$ & Albania, Bulgaria, Eurostat, Hungary \\
\hline 5. No projection & $\begin{array}{l}\text { Belarus, Bosnia and Herzegovina, Croatia, Cyprus, } \\
\text { Greece, Latvia, Liechtenstein, Lithuania, Malta, } \\
\text { Montenegro, North Macedonia, Slovenia }\end{array}$ \\
\hline
\end{tabular}

Note: The countries are listed in alphabetical order. The countries and agencies were given the opportunity to amend their placement in this table. As such, there are minor discrepancies between the information provided from the survey and the results from this table. Some countries use approaches from more than one category and are thus mentioned twice. ${ }^{\mathrm{a} B}$ Both frequentist and Bayesian approaches are included here. ${ }^{\mathrm{b}}$ Most countries rely not only on experts, but also on analyses of historical trends as well as on research on fertility determinants.

Austria). Spain reports that they adjust future fertility rates to a known beta function while using a panel of experts to inform MAC 15 and 50 years ahead. Less than half of the agencies state that they utilize a model to account for changing age schedules, with the Schmertmann model (2003) being the most frequently cited. Of the supranational agencies, Eurostat utilizes a mix of extrapolations from ARIMA models and assumptions of partial convergence across countries in the long run (Eurostat 2019b), while the UN applies a Bayesian hierarchical model to project the TFRs for each country (UN DESA 2019b).

Among those using a formal model, five agencies (including the UN) use a probabilistic approach (cf. Table 1). The Netherlands examines cohort and period patterns of fertility (by MAC and number of children) and then extrapolates forward by setting the future TFR and MAC. Alternatively, Iceland utilizes a functional modelling approach, wherein the long-term upper and lower bounds of the prediction interval are constrained to eventually converge to expert assumptions. The probabilistic approach used in Italy, meanwhile, involves a formal model, as described by Schmertmann (2003), and provides one scenario with prediction intervals based on probabilistic methods (cf. online Supplemental Data 1). The Faroe Islands use Hyndman's Demography package in $\mathrm{R}$ to form their probabilistic projection for fertility (Hyndman et al. 2019).

Fourteen countries report that they do not employ a formal statistical model, and instead base their fertility assumptions on evaluations of past developments, other methods and/or expert opinions (cf. online Supplemental Data 1 for examples). However, some of the methods applied by other agencies in this group are also model-based to some extent, albeit the modelling framework is not overarching.

Four out of five agencies $(\mathrm{N}=26)$ provide several alternatives, and the number of alternatives ranges from three (the most common, $\mathrm{N}=14$ ) to a maximum of nine (the $\mathrm{UN}$ ). 
Altogether, 22 agencies utilize advice from a panel of experts, and whereas 18 use expert opinion for all alternatives, the remaining four only use it for low and high variants.

The majority $(78 \%)$ of agencies report that they use the same methods for short-, medium-, and long-term fertility projections. Short-term is most commonly defined as three to seven years ahead. Among the seven agencies that use different methods for the different projection periods, two use 'nowcasts' of births for the first projected year (Germany and Eurostat), whereas one (the UK) uses an expert panel to obtain expectations of likely fertility levels in the short- and long-term. Four extrapolate recent trends forward in the short-term (Belgium, Denmark, Iceland and Poland). Several countries state that as projections move further from the base year, more weight is placed on assumptions that approach certain pre-determined values. Consequently, most long-term projections are held constant at some specified level.

\subsection{Projection Outputs and Their Usages}

Figure 2 provides a description of the level of detail in the fertility projection outputs for the respondent agencies. There is marked variation in the extent to which agencies produce detailed projection output data. Almost two-thirds of the agencies do not project fertility for any sub-groups. Of the remaining third, immigrant status is considered in one form or another. While Bulgaria only indicates immigrant status, Denmark separates between immigrants and their descendants. Six agencies project fertility based on country (and/or country group) of origin, three produce fertility by ethnicity, and another three by citizenship. Only two agencies, Slovakia and Sweden, reported that they produce parity-specific projections.

The most common way to assess the usage of the projections was via online web hits, page views, or downloads. Other measures mentioned included user needs, direct feedback from institutional stakeholders, media coverage, government feedback, and data requests. Five countries reported that they had no measures of projection usage.

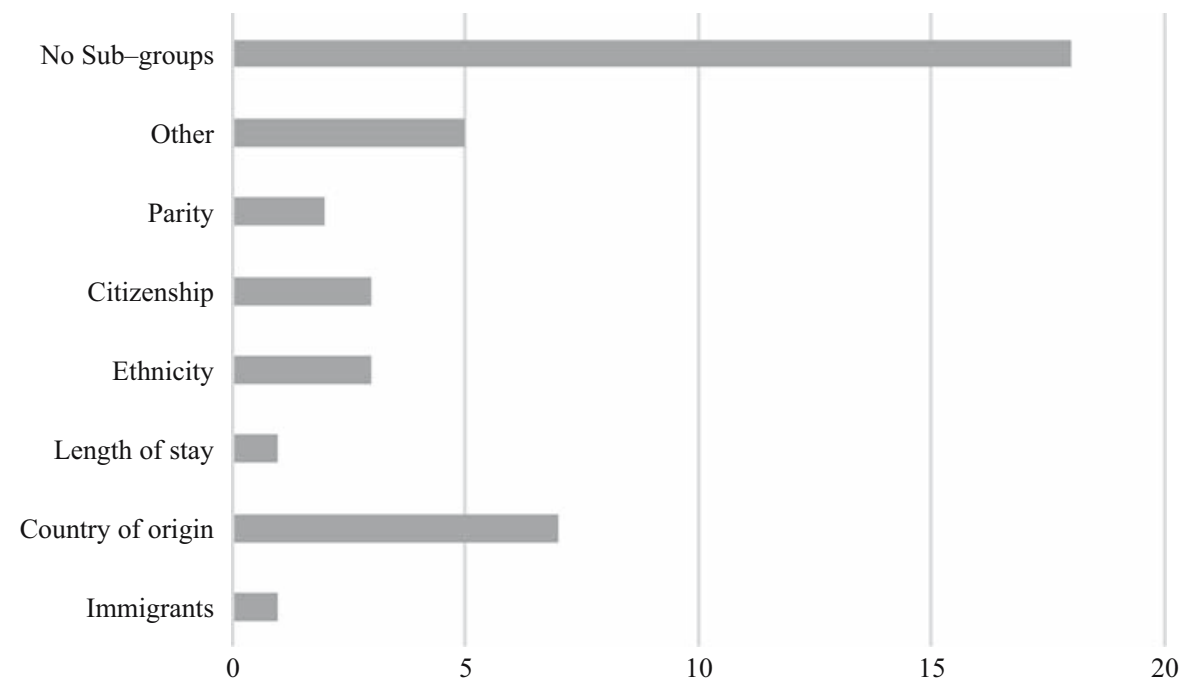

Fig. 2. Number of respondent countries by level of detail in fertility projection outputs.

Note: The total number of agencies is 32 . Contact information for agencies that produce specific outputs may be obtained from the authors. 


\subsection{Satisfaction With Recent Population Projections}

When asked to evaluate the most recent fertility projection, the vast majority $(\mathrm{N}=28)$ answered that the information available for making the fertility projections was adequate, while a few countries reported that they were exploring possibilities to increase the input data used in their fertility calculations (e.g., Denmark and Norway). Ukraine stated that they are working on plans to make annual or biennial updates.

The majority of the agencies also felt that enough time was spent on fertility projections $(\mathrm{N}=24)$, and that the frequency of updates was adequate $(\mathrm{N}=25)$. Seven agencies considered the time available to be insufficient (Belgium, Estonia, Finland, Luxembourg, Portugal, Slovakia, and the UK), while four indicated that the fertility projections were not updated frequently enough (Estonia, France, Poland, and Serbia). Two countries reported that poor data quality was an issue for their projection accuracy. Another two countries reported concerns that the number of scenarios is insufficient. The majority $(\mathrm{N}=27)$ stated that the number of scenarios produced is adequate. Interestingly, only one agency currently producing deterministic projections stated that a probabilistic approach would be preferable (Poland). Of those already using a probabilistic approach, Iceland suggested that a transition from a frequentist to Bayesian approach would be useful, primarily as a means through which they could attempt to formally incorporate expert opinion.

\subsection{Evaluations of the Accuracy of Projected Fertility}

A challenge that we encountered when registering and interpreting the survey responses was that the reporting in some cases was a mixture of what has been done, what is currently being done, and future plans or ongoing work. This is not surprising, since most agencies continuously strive to improve their data, methods and results, as also noted in the in-depth document review. Perspectives on discrepancies in trends between projected and observed fertility are shown in Figure 3. The question read: "Please give a short description of any discrepancies in trends between projected and actual fertility", and whereas the majority of agencies responded to the situation relating to their latest projection, some (especially those that publish frequently) also opted to include assessments from earlier projections with a longer time-horizon.

As noted previously, many agencies have tended to overestimate fertility levels in their projections (50\%). This was attributed primarily to a decline in the number of higher order births, although some also reported an unexpected rise in the number of childless women. This applied to, for instance, Denmark, Iceland, Luxembourg, the Netherlands, Norway, Sweden and Ukraine. Sweden has observed a decline in fertility since 2010, resulting in an overall overestimation of the projected fertility. However, for some groups of foreign-born women, they have underestimated fertility because birth rates were higher than assumed among recent arrivals. Other agencies reported a general underestimation of fertility (16\%), which was linked to difficulties in modelling short-run fluctuations in fertility, or in predicting changes in past trends, in this instance upwards. The latter applies for instance to Poland and Spain, who have seen an unexpected increase in fertility since their last projection. Only seven agencies report limited to no discrepancies between projected and observed fertility (Faroe Islands, Albania, Estonia, Greenland, Portugal, Serbia and Switzerland). 


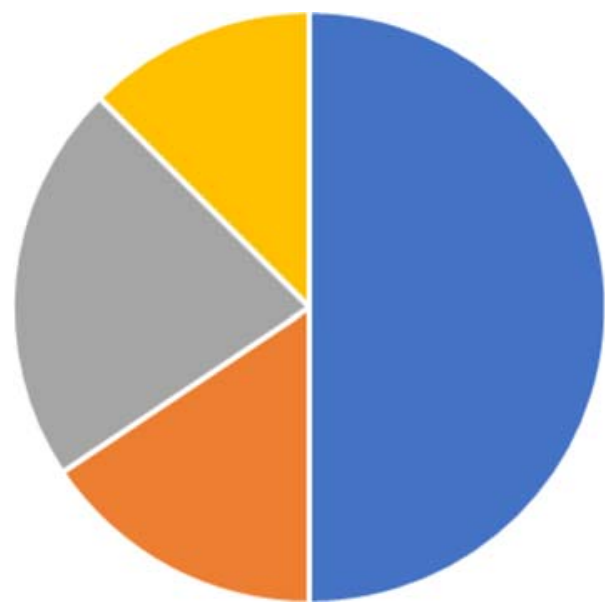

Projected fertility higher than observed

Projected fertility lower than observed

No marked discrepanics

Not stated

Fig. 3. Number of respondent countries by evaluations of discrepancies between projected and observed fertility.

Note: Contact information for agencies that observed deviations in a particular direction may be obtained from the authors.

While most agencies reported discrepancies between projected and observed fertility, it was interesting that no agency reported having a system in place to regularly assess discrepancies in the number of births or the TFR beyond the short-term. Moreover, most short-term evaluations were ad hoc in nature and primarily performed as part of preparations for the next round of projections. Consequently, few were able to provide references to formal assessments or evaluations of the accuracy of past fertility assumptions, and when they existed, the majority were available only in the language used in the official projections.

\subsection{Evaluations of the Strengths and Weaknesses of the Chosen Approaches}

When asked to (freely) list the strengths of the current way of projecting fertility (cf. Figure 4), some of the more common responses were satisfaction with the use of a formal model, quality of input data, transparency, high accuracy, and that the results are easy to interpret, explain and communicate to users. Several national agencies suggested their projections compared favourably against those made by Eurostat and the UN, while others mentioned the reasonably good accuracy of their past projections as a justification for the usefulness of their current approach.

Interestingly, some of the features that were mentioned as a strength by certain agencies, were mentioned as a weakness by others (cf. Figure 5). This was particularly evident when discussing the use of experts. Indeed, the use of experts was noted as being a strength by some agencies, for instance, in providing good insight and advice, and in representing a useful tool in justifying their assumptions for future fertility. Yet, other agencies viewed the use of experts as a weakness of their current method, wherein their fertility projections 


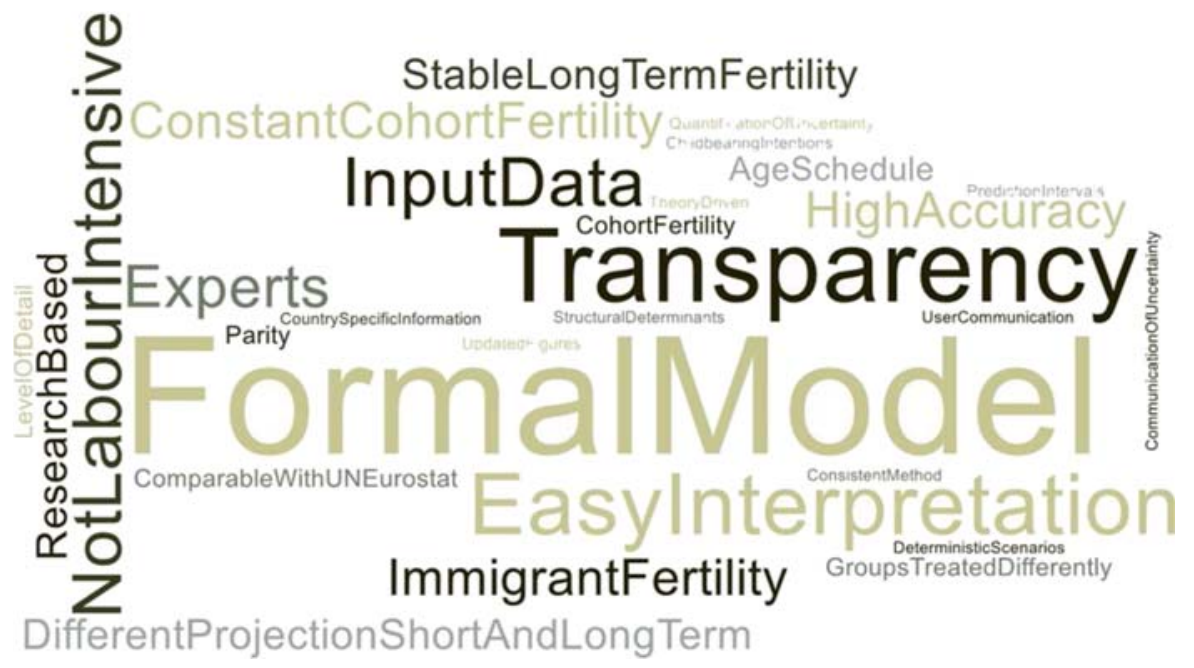

Fig. 4. Reported strengths of the current method.

Note: The size of each word indicates its frequency.

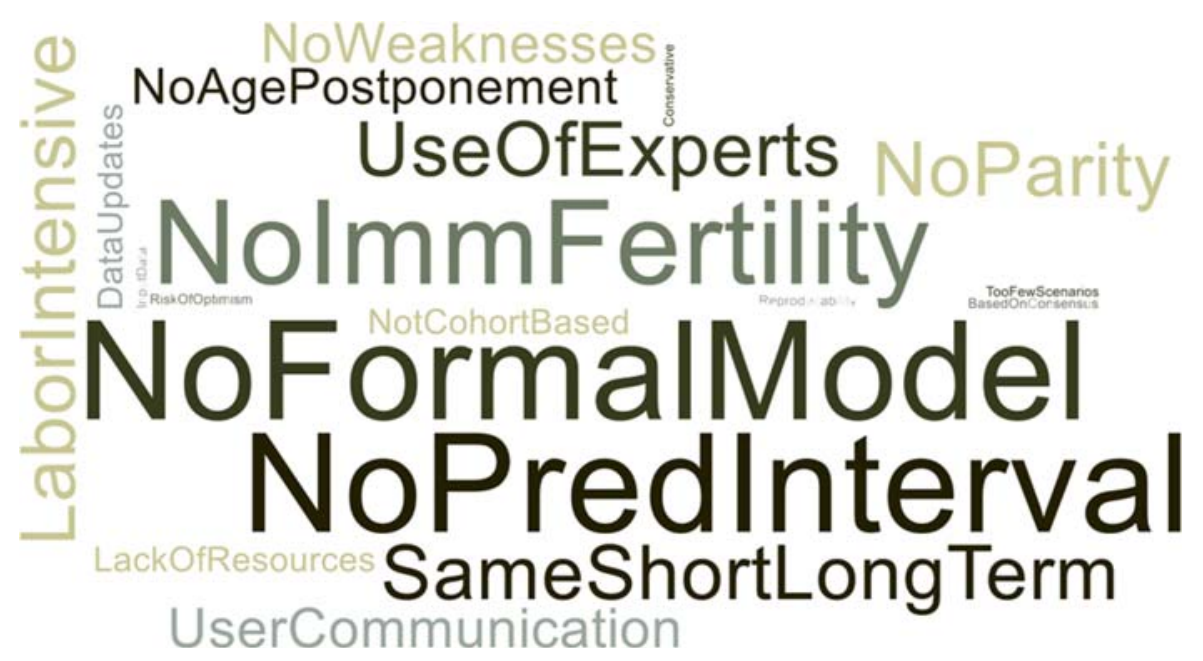

Fig. 5. Reported weaknesses of the current method.

Note: The size of each word indicates its frequency. NoPredInterval is short for 'No prediction interval'. NoImmFertility is short for 'No immigrant fertility'. DataUpdates refers to 'Infrequent data updates'.

could be deemed to be affected by assumption drift and unfounded expert consensus. Regardless of being a weakness or a strength, several agencies noted that it could be challenging to find relevant experts for fertility projections. 
There seems to be an agreement surrounding short- and long-term projections, as well as the number of determinants used to project fertility. Those who used different methods for short-, medium- and long-term projections viewed this as a strength, while those not differentiating between short-, medium and long-term projections deemed it as a weakness. Several discussed the value gained by using the most up-to-date data and incorporating multiple determinants of fertility in their projections. For those with a limited number of determinants of fertility, many listed other determinants of fertility they would have liked to include (e.g., MAC, parity, immigrant characteristics, and fertility intentions).

Despite the high number of agencies (75\%) indicating that they are satisfied with their current methods, many viewed their methods as having potential for improvement. Lack of formal models and prediction intervals, as well as the quality of data and limited resources were mentioned as constraining factors in the production and potential utility of their projections. Having labour intensive methods that are difficult to use, as well as posing a challenge in terms of reproducibility, was also mentioned as a weakness. Although generally satisfied with their current practices, agencies did report how challenging it was to know whether their chosen method was in line with the best practices of the field. Several discussed challenges surrounding communication of results to users, especially communicating the uncertain nature of projections. Some also had concerns about whether the users could be confused when being presented with multiple fertility alternatives.

\section{Discussion and Conclusion}

The majority (71\%) of Eurostat affiliated agencies produce fertility projections at the national level. All such agencies responded to the survey and the majority also helped to quality assure the information included here. Any errors in descriptions and/or interpretations remain, however, the responsibility of the authors.

The ever-present discussion of whether projections a priori are better or more valuable when framed in a probabilistic framework, with measures of uncertainty explicitly formulated, is not a topic of this study. Interested readers are referred to De Beer (2011) and Keilman (2018) for a thorough discussion of this issue. In summary, most countries use a deterministic approach to produce their fertility assumptions, although a number of agencies are experimenting with, or testing, stochastic approaches for possible future use.

\subsection{Process}

When producing population projections, one must form assumptions about future changes in the three demographic components: fertility, mortality and migration. The assumptions may be based on quantitative models, such as time series models or explanatory models. Models may be used within deterministic or stochastic frameworks, the latter based on either frequentist or Bayesian approaches, providing formalised estimates of uncertainty in fertility forecasts. Alternatively, assumptions may be argument based, i.e., they can be based on expert opinions about likely future developments in the main drivers of change. Whether projections are based on models or expert opinion, it is important to note that 
subjective choices and assumptions are always made at some point in the projection process (Armstrong 2001; De Beer 2011).

The TFR is the most widely used indicator of fertility. It is affected not only by changes in the average number of children per woman across successive cohorts, but by changes in the timing of fertility as well. Consequently, the timing of fertility should be accounted for in work on fertility assumptions. For the agencies who are currently not accounting for the timing of fertility (such as Norway), taking changing age patterns into account could be an important next step. Assuming that current age schedules will remain unchanged may result in inaccurate assumptions of future age-specific fertility rates, in line with the conclusions drawn for Norway in a review by Gleditsch et al. (2021).

It appears that most countries use a deterministic approach to produce their fertility assumptions. Only four agencies produce official probabilistic projections of fertility, while the UN produces both deterministic and probabilistic projections. Although a variety of approaches are currently being used, most agencies utilize a formal statistical model. Among those who do not, some rely in part on models for certain aspects of their assumption work.

Data quality, available resources and the expertise of the individuals working on the projections are all crucial for informing the choice of methods used in fertility projections. However, it is important to note that more than $70 \%$ of the responding agencies stated that they are satisfied with their current projection methodology. On the other hand, some countries, for instance Norway and Luxembourg, explicitly indicate a need to improve their fertility projections.

\subsection{Accuracy}

Population projections were initially developed to lay the basis for long-term planning, and tend, in general, to become less accurate the further away they are from the date of the projection (Bohk-Ewald et al. 2018; Myrskylä 2021). Thus, when projecting fertility for the next 50 years, the likelihood is that the projected numbers for 2050 will be less accurate than the projected numbers for 2025. It is perhaps unfortunate, therefore, that most agencies only evaluate the accuracy of their short-term projections. After all, the premises for accurate short-term projections are likely to differ from those that are relevant to the longer-term. Some criteria as to what comprises 'adequate' fertility projection results in which settings, appears warranted. Moreover, the evaluations are mostly informal and only performed in the period running up to the production of a new projection round. Beyond this, few agencies appear to regularly report the accuracy of their past projections to users. We would argue that assessing and documenting discrepancies in the short-, medium- and long-term in a more formal manner would help all producers to learn from past experiences and potentially identify a more appropriate methodology for their given situation. Such documentation would likely be useful for users of projections too, by helping to convey the inherent uncertainty of population projections, especially when they involve projections many years ahead.

It is beyond the scope of this study to compare the accuracy of the methods utilized across Europe. However, given the apparent diversity in the applied methods described above, such a task would certainly be useful for helping to identify whether there are 
particular methods that are more accurate than others. Indeed, there is potentially a learning opportunity from assessing and documenting projections in a more formal manner across different national contexts. With that said, any set of projections will inevitably be proven wrong. After all, demographers have a limited understanding of the complex social behaviours that underpin future population trends, and even when an understanding of certain mechanisms exists, the emergence of unforeseen external events can produce significant and unexpected changes in demographic behaviour and outcomes. Indeed, few foresaw the sudden increase in the number of births after the Second World War (the post-war baby boom), nor its abrupt end two decades later (the baby bust) (UNECE 2018), while at present we remain unsure even of the short-term effects of the COVID-19 pandemic on population dynamics. From this perspective, it seems appropriate to agree with the following statement from Keyfitz $(1981,579)$ : “[d]emographers can no more be held responsible for inaccuracy in forecasting population 20 years ahead than geologists, meteorologists, or economists when they fail to announce earthquakes, cold winters, or depressions 20 years ahead. What we can be held responsible for is warning one another and our public what the error of our estimates is likely to be". Fertility projections, and projections in general, assume that the observed long-term trends will continue into the future and do not aim to predict marked shifts in trends, although certain alternatives or scenarios may be designed to describe the potential effects of such events and shifts. Moreover, while fertility is likely to vary from year to year in the future, few agencies attempt to predict such short-term fluctuations more than 10-15 years ahead. As such, long-term assumptions could be interpreted as an average future level and not as an assumption of the most probable level for a single year.

\subsection{Transparency and User Communication}

Whether an extrapolation method or an explanatory model is used to make projections, responsible agencies need to make choices and assumptions about the type of method to be used, the base period, the selection of indicators and explanatory variables. Additionally, assumptions must be made concerning continuations of past trends and/or future changes in driving forces. Ideally, decisions and assumptions underlying the choice and application of methods should be made explicit, as this will allow users to evaluate their usefulness. Armstrong (2001) emphasizes two principles in particular: (1) provide complete, simple and clear explanations of methods; and (2) describe your assumptions. These principles imply that for projections to be transparent, the methods should be as simple as possible. If methods are complicated or not documented and explained well enough, projections may appear to be a 'black box'. To a certain extent, advanced models may be less accessible for non-expert users. Consequently, the choices made, the rationale for these choices and the impact of those choices, may be less well understood.

De Beer (2011) argues that users often cannot judge the quality of a projection, since neither the accuracy of projections, nor the plausibility of the alternative scenarios, are known at the time a projection is published. Users can, however, decide whether the projection process was reasonable, if they have information regarding the justification of the decisions and assumptions made. In other words, projections should be transparent. It is also useful if the consequences of these choices and arguments are presented, for instance by means of 
sensitivity analyses or by presenting alternative scenarios. Such reporting would likely be useful both for those working with fertility projections and for those using projections, as they would again illustrate the uncertainty associated with projecting the population.

Unfortunately, our survey only asked about usage. We did not ask specifically about whether user surveys or other interaction with users had been attempted, to assess how useful users find the respective projections. This should be examined in more detail in future studies to ensure that projection producers have some understanding of how well their methods and results are communicated to, and understood by, end users.

Readily available documentation in English is, to differing degrees, limited in most countries. Eurostat, Finland, Ireland, Luxembourg, the Netherlands, Norway, Spain, the United Kingdom, and the UN are exceptions, with extensive information available online in English and in published articles. Thus, it seems evident that most agencies would benefit from expanding their websites and/or published documentation to include a more detailed overview of their projections, methods, and accuracy, in English. This could potentially increase interaction between agencies and enhance the exchange of ideas on the topic of fertility projections. We recognize, of course, that this would require a commitment of precious resources and time.

Interestingly, although agencies appear to be aware of the inherent uncertainties associated with projections, the communication of this uncertainty does not appear to be a major concern. This runs contrary to what was indicated in a recent report from UNECE (2018). For instance, some of the agencies produce only one scenario, and have no plans to increase the number of alternatives. However, portraying alternative futures is only one way of communicating uncertainty, as elaborated on in the previous section.

\subsection{Conclusions}

Most European statistical agencies view their methods for fertility projections to be adequate, albeit with certain limitations. Although the stated limitations and/or challenges differ to some extent, several countries state that they are considering, and indeed testing, improvements to the approaches used in their fertility projections. This pertains both to the transparency of the models and/or assumptions made, the uncertainty associated with projections, and the short-term results. A common trend seems to be a slight overprediction of fertility levels in recent years in most countries. This appears to be a result of a stronger than expected decline in fertility in many countries during the past decade. Moreover, although most countries have observed a steady rise in maternal age, several countries appear not to account for changing age patterns in their fertility projections.

In summary, fertility projections will never be perfect predictions of the future as they are merely attempts at understanding what could happen to the current population if predefined assumptions of fertility materialise in future years. However, countries are likely to benefit from increased interaction and exchange of ideas. Attempts to increase such collaboration in the Nordic countries has already begun, having been initiated by the national statistical agency of Denmark in 2019, Norway in 2021, and to be followed-up by Sweden. The meetings and seminars organized by Eurostat are to be welcomed, as further exchange of information outside the Nordic area appears warranted to improve fertility projections and learning from countries and organizations that do well in this area. It is our 
hope that this study can be a helpful resource to increase knowledge of what our peers are doing and to improve learning and the exchange of ideas across European countries.

At the same time, an increased awareness and collaboration between national statistical agencies and the wider scientific community would be beneficial. As shown in this study, the practical approaches commonly taken by producers of official national fertility projections vary, to some extent, from the methods that appear in scientific publications. Potential discrepancies between 'actual practice', and what could be termed 'best practice', may be summarized as follows. First, published scientific methods generally tend to be more complex and frequently changing. Second, the methods focus largely on cohort fertility, which, while interesting, is less directly of use for national statistical agencies who focus on period fertility. Although ASFRs are projected to complete cohort fertility, and cohort fertility can easily be transformed into period fertility, the original use of the method is likely to guide research perspectives and findings (see e.g., Booth 2006). Third, the methods cannot be directly applied in existing cohort-component modelling frameworks, either because the format might be unsuitable (most models use ASFRs for smaller sub-groups of women such as immigrant women by sending country and/or duration of stay), or most frequently because there is a lack of resources in terms of time use and/or expertise. Finally, different aspects are often emphasized within the 'practical sphere', as compared to the wider scientific community. For example, many of the proposed methods focus on uncertainty and accuracy and, for most statistical agencies, the accuracy of the medium alternative is given more weight than that of other alternatives.

To conclude, we recommend a greater exchange of ideas and collaborations between the national statistical agencies, as well as between the producers of official projections and the wider scientific community. Several countries stated that as projections move further from the base year, more weight is placed on assumptions that level off at a specified value, in line with the 'freeze rate' method described in the scientific literature by Bohk-Ewald et al. (2018) and Myrskylä (2021). On the other hand, the scientific community could pay more attention to the needs of statistical agencies, perhaps by considering how new approaches can be implemented within the existing frameworks used by practitioners. This also includes considering the practicalities associated with producing a large number of estimates for multiple sub-groups over long periods of time, setting up a suitable framework for evaluations in more than the short-term, and facilitating the ease of use and communication of results. It is important that transparency is not lost when newly developed and/or more complex methods are implemented. Lastly, the costs and benefits of newly developed methods versus the tried and tested approaches that have been shown to perform reasonably well, need to be considered. More collaboration between the producers of fertility projections in different countries and academics working at the cutting edge of projection methodology could prove mutually beneficial in pooling expertise and knowhow to achieve the best possible projections.

\section{References}

Armstrong, J.S. 2001. "Standards and Practices for Forecasting." In Principles of Forecasting: A Handbook for Researchers and Practitioners, edited by J.S. Armstrong, 679-732. Norwell: Kluwer Academic Publishers. 
Ascher, W. 1979. Forecasting, an Appraisal for Policy-makers and Planners. London: The John Hopkins Press Ltd.

Bijak, J. 2011. Forecasting International Migration in Europe: A Bayesian View. Dordrecht: Springer.

Bohk-Ewald, C., P. Li, and M. Myrskylä. 2018. "Forecast Accuracy Hardly Improves with Method Complexity when Completing Cohort Fertility.” PNAS 115(37): 9187-9192. DOI: https:/doi.org/10.1073/pnas.1722364115

Bongaarts, J., and G. Feeney. 1998. "On the Quantum and Tempo of Fertility.” Population Development and Review 24(2): 271-291. DOI: https:/doi.org/10.2307/2807974.

Booth, H. 2006. "Demographic Forecasting: 1980 to 2005 in Review." International Journal of Forecasting 22(3): 547-581. DOI: https:/doi.org/10.1016/j.ijforecast.2006. 04.001.

Cappelen, Å, T. Skjerpen, and M. Tønnessen. 2015. "Forecasting Immigration in Official Population Projections Using an Econometric Model." International Migration Review 49(4): 945-980. DOI: https:/doi.org/10.1111/imre.12092.

Costemalle, V. 2020. "Bayesian Probabilistic Population Projections for France." Economie et Statistiques 520-521: 29-47. DOI: https:/doi.org/10.24187/ecostat.2020. 520d.2031.

De Beer, J. 1990. "Projecting Age-Specific Fertility Rates by Using Time-Series Methods." European Journal of Population 5(4): 315-346. DOI: https:/doi.org/10. 1007/BF01796791.

De Beer, J. 2011. Transparency in Population Forecasting: Methods for Fitting and Projecting Fertility, Mortality and Migration. Amsterdam: Amsterdam University Press. Disney, G., A. Wiśniowski, J.J. Forster, P.W.F. Smith, and J. Bijak, 2015. Evaluation of Existing Migration Forecasting Methods and Models. Southampton: University of Southampton.

Eurostat. 2019a. Population (Demography, Migration and Projections): Population Projections. Eurostat. Available at: https://ec.europa.eu/eurostat/web/populationdemography-migration-projections/population-projections-data\#. (accessed November 2020).

Eurostat. 2019b. Technical Note: Summary Methodology of the 2018-based Population Projections (EUROPOP2018). European Commission Eurostat. ESTAT/F2/PRO/2019. Available at: https://ec.europa.eu/eurostat/cache/metadata/Annexes/proj_esms_an26.pdf. (accessed November 2020).

Eurostat. 2021. Fertility Statistics. Available at: https://ec.europa.eu/eurostat/statisticsexplained/index.php/Fertility_statistics\#live_births_per_woman_in_the_EU_in_2019 (accessed April 2021).

Frank Hansen, M., and P. Stephensen. 2013. Denmark's Future Population: Population Projections 2013. DREAM report 2013. Available at: https://dreamgruppen.dk/media/ 10640/r2013_01.pdf (accessed December 2020).

Gleditsch, R.F., and A. Syse. 2020. "Ways to Project Fertility in Europe: Perceptions of Current Practices and Outcomes.” Discussion Papers No. 929. Oslo: Statistics Norway. Available at: https://www.ssb.no/en/forskning/discussion-papers/_attachment/420678? _ts $=171 \mathrm{f} 426 \mathrm{c} 610$ (accessed December 2020). 
Gleditsch, R.F., A.F. Rogne, A. Syse, and M. Thomas. 2021. "The Accuracy of Statistics Norway's National Population Projections.” Discussion Papers No. 948. Oslo: Statistics Norway. Available at: https://www.ssb.no/449812/the-accuracy-of-statistics-norwaysnational-population-projections (accessed April 2021).

Hadwiger, H. 1940. "Eine Analytische Reprodutionsfunktion für Biologische Gesamtheiten." Skandinavisk Aktuarietidskrift 23(3-4): 101-113. DOI: https:/doi.org/10.1080/ 03461238.1940.10404802.

Hyndman, R.J., and S. Ullah. 2007. "Robust Forecasting of Mortality and Fertility Rates: A Functional Data Approach.” Computational Statistics Data Analysis 51: 4942-4956. DOI: https:/doi.org/10.1016/j.csda.2006.07.028.

Hyndman R.J., H. Booth, and F. Yasmeen. 2013. "Coherent Mortality Forecasting: The Product-ratio Method with Functional Time Series Models." Demography 50: 261-283. DOI: https://doi.org/10.1007/s13524-012-0145-5.

Hyndman, R.J., H. Booth, L. Tickle, and J. Maindonald, 2019. Package 'demography'. Available at: https://cran.r-project.org/web/packages/demography/demography.pdf (accessed June 2021).

INSEE. 2020. Population Projection: Description. Institut national de la statistique et des études économiques. Available at: https://www.insee.fr/en/metadonnees/source/serie/ s1316. (accessed November 2020).

Keilman, N. 2018. "Probabilistic Demographic Forecasts." Vienna Yearbook of Population Research 16: 1-11. DOI: https:/doi.org/10.1553.populationyearbook2018s025.

Keyfitz, N. 1981. "The Limits of Population Forecasting." Population and Development Review 7(4): 579-593. DOI: https:/doi.org/10.2307/1972799.

Lee, R.D., and L.R. Carter. 1992. "Modelling and Forecasting U.S. Mortality." Journal American Statistical Association 87: 659-671.

Li, N., and R. Lee. 2005. "Coherent Mortality Forecasts for a Group of Populations: An Extension of the Lee-Carter Method." Demography 42: 575-594.

Myrskylä, M. 2021. "Fertility Forecasts in the Nordic Countries." Seminar presentation at What Happened to Nordic Fertility? 2-3 February 2021. Available at: https://invest.utu.fi/events/what-happened-to-nordic-fertility (accessed June 2021).

Raymer, J. and A. Wiśniowski. 2018. "Applying and Testing a Forecasting Model for Age and Sex Patterns of Immigration and Emigration." Population Studies 72(3): 339-355. DOI: http://dx.doi.org/10.1080/00324728.2018.1469784.

Schmertmann, C. 2003. "A System of Model Fertility Schedules with Graphically Intuitive Parameters.” Demographic Research 9(5): 81-110. DOI: http://dx.doi.org/10. 4054/DemRes.2003.9.5.

Schmertmann, C., E. Zagheni, J.R. Goldstein, and M. Myrskylä. 2014. "Bayesian Forecasting of Cohort Fertility." Journal of the American Statistical Association 109(506): 500-513. https://doi.org/10.1080/01621459.2014.881738.

Sobotka, T. 2017. "Post-Transitional Fertility: The Role of Childbearing Postponement in Fuelling the Shift to Low and Unstable Fertility Levels." Journal of Biosocial Science 49(S1): S20-S45. DOI: https./doi.org/10.1017/S0021932017000323.

Sobotka, T., K. Zeman, R. Lesthaeghe, and T. Frejka. 2011. "Postponement and Recuperation in Cohort Fertility: New Analytical and Projection Methods and their Application." European Demographic Research Paper. Available at: https://www.vub.- 
be/demography/wp-content/uploads/2016/02/EDRP2-2011_Sobotka_Zeman_Lesthaeghe_Frejka.pdf (accessed March 2021).

Statistics Denmark. 2019. Statistical Documentation for Population Projections 2019. Copenhagen: Statistics Denmark. Available at: https://www.dst.dk/da/Statistik/dokumentation/statistikdokumentation/befolkningsfremskrivnig (accessed November 2020).

Statistics Finland. 2019. 2019, Quality Description: Population Projection 2019-2070.

Helsinki: Statistics Finland. Available at: http://www.stat.fi/til/vaenn/2019/vaenn_2019 _2019-09-30_laa_001_en.html (accessed November 2020).

Statistics Finland. 2020. Population Projection. Helsinki: Statistics Finland. Available at: http://www.stat.fi/til/vaenn/kas_en.html (accessed November 2020).

Statistics Poland. 2014. Population Projection 2014-2050. Warsaw: Statistics Poland. Available at: https://stat.gov.pl/en/topics/population/population-projection/populationprojection-2014-2050,2,5.html (accessed November 2020).

Statistics Sweden. 2019. Declaration of Quality: Population Projections. Stockholm: Statistics Sweden. Available at: https://www.scb.se/contentassets/77d1f12a07214b528 b2141df9bb818cf/be0401_kd_2020_11_200310.pdf (accessed November 2020).

Syse, A., M. Thomas, and R.F. Gleditsch. 2020. Norway's 2020 Population Projections: National Level Results, Methods and Assumptions. Oslo: Statistics Norway. (Report 25/2020). Available at: https://www.ssb.no/en/befolkning/artikler-og-publikasjoner/norways-2020-population-projections. (accessed November 2020).

UNECE (United Nations, Economic Commission for Europe). 2018. Recommendations on Communicating Population Projections. New York/Geneve: United Nations. (ECE/ CES/STAT/2018/1). Available at: https://unece.org/fileadmin/DAM/stats/publications/ 2018/ECECESSTAT20181.pdf. (accessed November 2020).

UN DESA (United Nations, Department of Economic and Social Affairs). 2013. Explaining Differences in the Projected Populations between 2012 and 2010. Revisions of World Population Prospects. Population Facts. New York: UN DESA. Available at: https://www.un.org/en/development/desa/population/publications/pdf/popfacts/popfacts_2013-10.pdf (accessed November 2020).

UN DESA (United Nations, Department of Economic and Social Affairs). 2019a. World Population Prospects 2019 - Data Booklet. New York: UN DESA. Available at: https://population.un.org/wpp/Publications/Files/WPP2019_DataBooklet.pdf (accessed November 2020).

UN DESA (United Nations, Department of Economic and Social Affairs). 2019b. Methodology of the United Nations Population Estimates and Projections. World Population Prospects 2019. New York: UN DESA. Available at: https://population.un.org/wpp/Methodology/ (accessed November 2020).

UN DESA (United Nations, Department of Economic and Social Affairs). 2019c. Definition of Projection Variants. World Population Prospects 2019. New York: UN DESA. Available at: https://population.un.org/wpp/DefinitionOfProjectionVariants/ (accessed November 2020).

Vandresse, M. 2020. Modelling Fertility for National Population Projections: The Case of Belgium. Brussel: Federal Planning Bureau. Available at: https://www.plan.be/publications/publication-2052-en-modelling_fertility_for_national_population_projections_the_case_of_belgium (accessed December 2020). 
Zeman, K., E. Beaujouan, Z. Brzozowska, and T. Sobotka. 2018. "Cohort Fertility Decline in Low Fertility Countries: Decomposition Using Parity Progression Ratios." Demographic Research 38(25): 651-690. DOI: https://doi.org/10.4054/DemRes.2018.38.25.

Received December 2020

Revised April 2021

Accepted June 2021 